The Third Pole: Journal of Geography

Vol. 17: 1-20, 2017

Department of Geography Education,

Central Department of Education, T.U., Kathmandu, Nepal

\title{
SPACE OF GEOGRAPHY CONTENT IN SOCIAL STUDIES OF SCHOOL EDUCATION CURRICULUM IN NEPAL
}

\section{Krishna Prasad Poudel ${ }^{1}$}

\begin{abstract}
Social studies education (SSE) is placed among the major academic disciplinary subjects within the school curriculum even from the primary/basic to the secondary level. It is a compulsory subject in the Secondary Education Examination (SEE) as well as it was also in the School Leaving Certificate (SLC) Examination. Importance of the subject itself has no question, despite that the content inside the subject and the delivery of the subject to the student are the major concerns. By the principle, the SSE is the combination of knowledge, skill and values of the society. It is the composition of the academic disciplinary subjects of social sciences, such as, geography, history, sociology, anthropology, civics, economics, psychology, culture including numbers of social issues and agendas in an integrated form including the past events in the study enables and inspires students to understand the present and become the bona fide citizens. The present paper has focused the position of geography content in the social studies of school education curriculum in Nepal. It has been over viewed in the context of content incorporated inside the subject according to the grades from basic to the secondary level and the delivery systems in each chapter. At the end, the final outcomes have been summarized as a form of suggestions to improve the disciplinary development of geography content in the social studies of school education curriculum.
\end{abstract}

Keywords: Social studies education, geography, academic discipline, curriculum structure, contemporary development.

1 Dr. Poudel is a Professor of Geography Education, Central Department of Education, T.U. Kirtipur, Email: kpoudel.pokhara@gmail.com 


\section{Introduction}

At present, social studies education (SSE) is prescribed as a compulsory subject in school education from grade 1 to 10 in Nepal. At the university level, it is kept as one of the elective subjects at the Bachelors' Degree in Education (B.Ed.). It is also envisaged to introduce in the university education as a specialization course at Bachelors' Degree in Education (B.Ed) and also at Master's Degree in Education (M.Ed.) in the near future. Recently, the proposal is also made for the Open and Distance Learning (ODL) mode as well as for the face-to-face mode of teaching at Faculty of Education (FoE) of the Tribhuvan University. The need of teaching social studies university level has been felt to fulfill the shortage of specialized teaching human resource at school level. The anecdotal reports and comments in various levels found that there are no specialized and trained human resources for teaching social studies course at school level due to the absence of academic programmes for its specialization in the university education system. The FoEhas Master's Degree progrmme in individual social studies subjects like geography education, history education, political science education and economics education, however, these subjects are mainly designed for the social studies group not for the specialization of social studies within an integrated form. These have separated pillar-structured base as a concept developed in the Humanities and Social Sciences. Therefore, there is no specifically designated social studies specialized human resource in the country. So far, the subject is usually taughtat school by any subject graduates. Even the Teacher's Service Commission of Government of Nepal announces vacancies for the post of social studies teacher with the basic eligibility for any subject specialization in their graduate and post-graduate levels. It has been raising the question of the philosophical ground of the subject itself.

Elsewhere, numbers of formal and informal talks have been pointing the quality of syllabus, structural coherence of the contents designed within the curriculum, philosophical ground of the subject itself, the teaching methods and delivery systems, teaching and learning tools, aids and supporting materials and finally the outcome of the course. Due to such efforts, the SLC and SEE result is satisfactory but not good.In total the pass percentage of the social studies subject was $74.21 \%$ in 2014 A.D., 83.74 in 2015 A.D., of the SLC Examination Board and it was over $75 \%$ students secured D+ in the SEE examination of 2016, thoughthe general comments among the students entailed that the social studies course is not a comfortable subject to learn. Within these circumstances, this paper hasbeen pursuing answer of some fundamental questions related with social studies in general and geography content in particular. What is the 
philosophical route of the social studies education as an academic discipline? Where is the space of geography content in the social studies of school education curriculum in Nepal? What are the contents incorporated within the social studies curriculum? How is the geography subject treated by the education planner in the Nepalese education system? What are the practices teaching SSE in other countries of the world? Amidst these questions, the study has been explored some of the factual evidences of practices in the SSE of school curriculum in Nepal.

\section{Methods and Materials}

This paper is mainly based on the review of the curriculum and related materials of SSE. Review has been made the contents, comments and observations available elsewhere in cloud and crowd. Following the questions envisaged in the context of the curriculum at the global arena were reviewed by Google searching and based on the available open source library. In the Nepalese context the published documents from the Ministry of Education, Government of Nepal were reviewed. Similarly, the curriculum and text books of social studies published by the Curriculum Development Center (CDC) were reviewed.

\section{The Route of Social Studies Education}

The dictionary meaning of social study is a part of a school or college curriculum concerned with the study of social relationships and the functioning of society and usually made up of courses in history, government, economics, civics, sociology, geography, and anthropology (http://www.merriam-webster.com/dictionary/ social\%20 studies). Further, it is defined as a course of study that deals with human relationships and the way society works. It has been treated as the integrated study of the social sciences and humanities to promote civic competence. The contemporary society is highly competitive. It has usually put the public in pressure and move from origin place to elsewhere for various purposes. Because of the mobility of people for different purposes the conventional value system in the society are being gradually converting to the mixed culture, and social pluralism. The present day society is becoming more complex and with multi identities. The complexities further added by geographical, cultural, social, historical, governance dividends. In such circumstances social study at their beginning of school education has to be placed within the real practical and meaningful learning. The National Council for Social Studies (NCSS), the professional organization of SSE, has played an essential role since 1921 (www.ncss.org). The NCSS definition seems to be a good place to start the discussion of how to teach social studies 
in an elementary school classroom to the advance levels. It has envisaged the social studies as it provides coordinated, systematic study drawing upon such disciplines as anthropology, archaeology, economics, geography, history, law, philosophy, political science, psychology, religion, and sociology, as well as appropriate content from the humanities, mathematics, and natural sciences. The primary purpose of social studies is to help young people develop the ability to make informed and reasoned decisions for the public good as citizens of a culturally diverse, democratic society in an interdependent world (NCSS Task Force on Standards for Teaching and Learning in the Social Studies, 1993, p. 213). The NCSS definition states the topics covered in social studies and clarifies the purposes of social studies teaching and learning.

Barth (1993) provides a simpler definition of social studies which is the interdisciplinary integration of social science and humanities concepts for the purpose of practicing problem solving and decision making for developing citizenship skills on critical social issues'. As per the NCSS, that the "core mission of SSE is to help students develop the knowledge, skills, and values that will enable them to become effective citizens" (NCSS Task Force on Revitalizing Citizenship Education, 2001, p.319).

Manitoba Education, Citizenship and Youth, in collaboration with Manitoba Educators (2005) over viewed the world of social studies, where students have opportunities to interact with each other in democratic groups and communities, and to acquire the knowledge, values, and skills they need to become active, responsible citizens within the Canadian society. The report visualized as they grow and learn the skills of citizenship, they not only contribute to their learning communities, but also contribute to the betterment of their society. The vision was set for the production of better citizenships in the pluralistic society. The goals of the social studies enable students to acquire the skills, knowledge, and values necessary to understand the world in which they live, to engage in active democratic citizenship, and to contribute to the betterment of thesociety (Manitoba Educators, 2005, p.3).

In the Nigerian experience the social studies has been viewed within the cultural values. This is more appropriate in the pluralistic society where cultural values played significant role in the society. In such context the subject designed and evolved to foster in learners a better understanding of the cultural values that guides the interactions of man with his physical and social environment. It is, the most integrated of all subjects at the various levels of education and this has made it to be broad and contain different kinds 
Krishna Prasad Poudel / Space of Geography Content in Social Studies of School Education ...

of elements. This broad nature makes social studies the most appropriate subject in the school curriculum to meet the cultural values and moral goals of the society (Adediran and Adenike 2013, p. 71).

Miscoand Hamot (2012)affirmed that social studies as the study of people. Social studies should help students acquire knowledge, master the processes of learning, and become active citizens. The knowledge children acquire as a part of social studies tends to be the highest priority for teachers, parents, and the children. The common perception is that this is what social studies is all about. This is too limited a view because social studies must be a vehicle for children to become better communicators, thinkers, researchers, computer users, and artists. Finally, the ultimate goal of social studies is to make over children active citizens in our society, as our students use the knowledge they have acquired and the processes they have mastered to make communities, the nation, and the world better places. This is the position of the NCSS, that the "core mission of SSE is to help students develop the knowledge, skills, and values that will enable them to become effective citizens" (NCSS Task Force on Revitalizing Citizenship Education, 2001, p. 319, cited in Zarrilo, 2012).

Within this conceptual ground it is necessary to point out here about the contents of the social studies. It would be worthwhile to note it as of the thematic guidelines of the social studies where 10 different thematic areas and the questions for explorations have been suggested as followings (NCSS, 2010 Sampler by Parker, 2010,P.3):

- Culture: (What is culture? How does culture unify a group of people? What is cultural diversity, and how does diversity develop both within and across cultures?)

- Time, Continuity, and Change: (What happened in the past? How do we know about the past? How was life in the past similar to and different from life today?)

- People, Places, and Environments: (What are the physical and human characteristics of place? How do people change the environment, and how does the environment influence human activity? How do simple geographic skills and tools help humans understand spatial relationships?)

- Individual Development and Identity: (How have others influenced who I am and who I am becoming? How can I learn to cooperate and collaborate with others? How do children in other parts of the world grow and learn?) 
- Individuals, Groups, and Institutions: (To what groups do I belong? How do the groups to which I belong influence me, and how do I influence them? How do civic, educational, governmental, and religious organizations function in our community, state, and nation?)

- Power, Authority, and Governance: (What is government? How are individual rights protected within the context of majority rule? What are the rights and responsibilities of citizens in a constitutional democracy?)

- Production, Distribution, and Consumption: (Why can't people have everything that they want? How do people decide what to produce and what services to provide? How does the availability of resources influence economic decisions?)

- Science, Technology, and Society: (What do we mean by science and technology? How can science and technology be used to address individual, social, and global problems or issues? What are various types of media, and how do media influence us?)

- Global Connections: (What are examples of global connections in our community or state, and what are the effects? What are persistent and emerging global issues? What actions can we suggest and take in response to global changes?)

- Civic Ideals and Practices: (What are civic ideals? What are civic practices? What are examples of situations in which civic ideals and practices need to be more closely aligned?)

The content suggested here has been included the major thematic areas of all social disciplines including geography. The framework has further clarified about the standards which have been developed both in social studies and in many of the individual disciplines that are integral to social studies, the question arises: What is the relationship among these various sets of standards? The answer is that the social studies standards address overall curriculum design and comprehensive student learning expectations, while state standards and the national content standards for individual disciplines (e.g., history, civics and government, geography, economics, and psychology) provide a range of specific content through which student learning expectations can be accomplished. The NCSS curriculum standards offer a set of principles by which content can be selected and organized to build a viable, valid, and defensible social studies curriculum for grades 
Krishna Prasad Poudel / Space of Geography Content in Social Studies of School Education ...

from pre-K through 12 . They provide the necessary framework for the implementation of content standards (Parker, 2010, p.5).

\section{Initiation in Nepal}

In Nepal, the need of social studies was felt in the early 1950s. 'Education in Nepal' report of the Nepal National Education Planning Commission (1956) clearly envisaged the role of citizens and the duties and responsibilities to perform. The report has stated that to meet the purposes and objectives of primary education the curriculum must be provided learning experiences in the common and compulsory for all children (NNEPC, 1956, p. 89). Social studies was one of them to introduce from the grade one to teach how mankind lives. The report has further clarified that social studies experiences should be centered on the social activities of mankind, especially those naturally engaged in by children. They should emphasize cooperative, constructive behavior among children and adults. They should develop desirable social attitudes that promote community living. They should promote understandings of their own and other cultures. They should develop appreciations of the democratic way of life and the responsibilities of democracy (NNEPC, 1956, p.90).The contents were proposed as

- Grade I - life in school and at home

- Grade II - life in the neighbourhood

- Grade III - life in the region - the valley, the hills, or the Terai

- Grade IV - life in the other parts of Nepal

- Grade V - life in the outside of Nepal

Those themes provided for the gradual expansion of the child's vision from his immediate environment to as broad a world outlook as possible for them to comprehend. They move from the immediate to the remote, from the concrete to the more abstract. Further, that has capability of integrating bases for developing the skills of other subjects. Stated illustrations a study of life in the neighborhood offers opportunities to understand science, nature study, and health, and to practice skills by painting or drawing scenes of the village, by learning to use money, by speaking and writing about incidents observed in the village, and by reading stories of village life.

The report has further detailed the contents of the social studies based on the experiences those help young people to better understand and appreciate, and to practice, democratic 
relationships among mankind. In the secondary level each student should be familiar with the political and economic geography of Nepal, Asia, and the rest of the world, the historical antecedents of Nepal and Asia, and significant phases of world history; the origin, meaning, and development of culture, and the culture of different people of the world; political forms and their origins; economics of trade, industry, agriculture, and commerce; the government of Nepal in detail, and general concepts of government in other countries; community life in Nepal, social problems, religion, and other problems, that affect man's social life. Each student should develop skills in social research, meeting and solving problems, community survey, working cooperatively with others, parliamentary procedures, self expression, self analysis, and using maps, time lines, graphs, charts, pictorial display, etc. to receive and express ideas. The emphasis there was not on segmented bits of knowledge to be retained for possible future use, but on the immediate day to day, self directed and purposeful behavior that enable youth to become independent, resourceful, useful members of adult society.

The route of SSE can be clearly visualized in the early 1950s. the contents were well structured by including major thematic areas of the society. The geography content was focused for social, economic and environmental issues. The Commission has suggested the following curriculum themes for social studies to follow, and strengthen (NNEPC, 1956, p.105).

- Grade VI - how people live (food, shelter, clothing, vocations, etc.)

- Grade VII - great men and women who have made Nepal

- Grade VIII - life in the countries of Asia

- Grade IX - social, economic, and political life in Nepal

- Grade X - world culture and government

The National Education System Plan (NESP) in 1971-1976 of the His Majesty's Government of Nepal was the first structured curriculum designed to achieve the aims of education (HMG, 2071, P.36). NESP (1971-1976) had allocated $20 \%$ of the weightage among the all at the class 1 to 3, of the total 650 marks, it was allocated 100 full marks. Similarly, from class 4 to 7 (lower secondary level) the social studies had been given weightage of $13 \%$ or 100 full marks out of 1000 in total. However, at the secondary levels (class 8 to 10) the social studies was replaced with history and geography by 12 $\%$ weightage or 100 full marks out of 900 in total. In the vocational high-school social 
Krishna Prasad Poudel / Space of Geography Content in Social Studies of School Education ...

studies was combined with history, geography and Panchayat but the weightage was the same with general school (12\%)(HMG, 1971).

After the 1990s democratic restoration, the NESP guided education systems were removed and several changes have been made in the education systems too along with major political changes in the country. The National Education Commission (1992)was constituted in the Ministry of Education and Culture and Social Welfare of the HMG of Nepal. The Commission had recommended several changes in the education systems of the country. It has again recommended 100 full marks Social Studies course for primary (Grades 1 to 5), Social Education of 100 full marks in lower secondary (Grade 6 to 8 ) and 100 full marks for secondary (Grade 9 and 10). There were no consistencies in the terminology of the discipline. Somewhere they had used social studies and social education. Subjects like history and geography were not taught at all. It was recalled from the National Education System Plan 1971 (MoECSW, 1992).

In the education plan and policies of Nepal, the subject social studies was kept in different forms and modalities. The vision of school education was expected to prepare citizens dedicated to promote and protect democracy and human rights. They should possess attributes like dignity of labor, committed to education, enterprising, disciplined, and capable enough towithst and the personal, social and national challenges of the twenty first century. The National Curriculum Framework (2007) was the main document of school education and framed the visions and goals of national curriculum, policy and guidelines of school level education. The principal learning areas were organized in the process of designing curriculum. The major learning areas and subjects were: Language (local/mother tongue, national and international), Mathematics, Social Studies, Creative Arts, Science, Health and Physical Education, Population and Environment Education, Information and Communication Technology, local need based studies, everyday jobs, occupation and trade (CDC, 2007, p.33).

According to the Framework the basic education (Grade 1-8) was to develop the innate ability of each child through child centered education. Its main aim was to produce citizens who are loyal to the nation and democracy and aware of their responsibility towards the social and natural environment. Students were expected to be competent in communicating ideas, independent, hardworking, and health conscious and morally sound. In total the Framework had envisaged 14 specific objectives for the basic education, not a single objective has spelled out for the understanding of the 
geographical dimension of the country. However, history, culture and value systems of the society were spelled out as objectives of the basic education. Similarly, the aim of secondary level education (Grade 9 to 12) envisaged to produce competent and healthy citizens who can contribute to economic development and are familiar with national traditions, cultural and social heritage, and democratic values. Its main aim was to produce skilled human resource capable to furnish solid contributions to the allround development of the country and make them mindful citizen by imparting basic knowledge required for university education. The Framework has spelled out 12 specific objectives for the secondary education and where two objectives regarding familiarize with the national history, culture, geography, economics, ethnic and cultural diversity and environment for nation's development by promoting national unity, cordiality and peace and develop attitudes to respect individual differences in terms of gender, disabilities, social, economic, geographical, ethnic and cultural variations and be active in building inclusive society by being aware of social evils like racial untouchability were envisaged (CDC, 2007, p. 43). At least the Framework has accepted the existence of geography at the secondary level. Even the NCF (2007) was prepared by a group of national academicians after the peace accord of ten years long so-called people's war which has been widely commented the situation aroused because of economic hardship among the people due to the geographical complexities of the country. However, the education experts did not feel to include the study of geographical dimension of the country to the school education curriculum.

MoE (2016) has envisaged the national curriculum framework for the entire education cycle (1 to 12) including core skills such as critical thinking and collaboration with promoting the use of digital and interactive teaching learning resources and the integrating life-skills, soft skills and value based education. It has adapted the vision of education towards the equity, equality and access to all, efficiency, governance and accountability and resilience in education within the circumstances of current transformation of the country to federal democratic republic along with the constitutional provision and legal measures as mentioned in the Constitution of Nepal 2015. The Fundamental Right of basic education has been envisaged to free and compulsory and free secondary education within the framework of 'Education for All' (EFA). The devolution of governance and management of education to the local level is another major way forward which has been adopted by the SSDP2016/17-2022/23 (MoE, 2016). The Plan has clearly spelled out the adding of some new contents by observing the post-disaster events where disaster risk reduction (DRR) and school safety towards the management sectors are recommended. 
Krishna Prasad Poudel / Space of Geography Content in Social Studies of School Education ...

However, it is silent on responsibility of curriculum development. Provincial history, geography, civics, culture, social values, norms and several social dimensions, including area studies, regional characteristics, the complex geographical dimension of the nation, remain important for the values and life-skills education systems which should be in the center of the education and should be included in the curriculum framework of social studies education from basic to the higher secondary education. But, these contents are neither spelled out nor given any importance.

\section{Current Structure of Social Studies Education Curriculum in Nepal}

After 2005, Nepal has experienced major political shift. The country is now transforming to federal democratic republic system. More power has been supposed to be devolved to the local governance system. Education system is one of such proposed authorities to be devolved to the local institutions for curriculum development, management and mobilization. However, the full-fledged mechanism yet to be developed, the major framework has been envisaged School Sector Development Plan (2016/17-2022/23) (MOE, 2016). The SSDP has encompassed formal and non-formal education, whereas the formal education has been categorized into one year early childhood education and development, basic education from grade 1 to 8 and secondary from grade 9 to 12 . Most of the course structure are still running as of the CDC framework as envisaged by NCF (2007). The social studies curriculum for the primary level (grade 1 to 3 ) has been developed by Primary Education Curriculum (2006)framework where social studies and creative arts have been included (CDC, 2008). Despite the primary grade as prescribed by the CDC (2008), the curriculum structure is almost similar up to the grade 5 . The objectives of the curriculum were put forward by placing emphasis on the practical education system. It was expected that the learners were enabled to identify and solve their own problems and thereby based on their own thinking process, skills, ability, interest and choice which foster their ability in different areas to encourage active participation in learning and life skills at large (CDC, 2008, p. 19).

To achieve the stated objectives, the curriculum has designed the following to achieve the following specific grade-wise objectives and specific lessons were suggested in the prescribed textbooks and also instructed the teachers accordingly (CDC, 2008, p.21).

- To give introduction of self, one's family and neighbor

- To be aware of social evils, untouchably, conservatism etc. 
The Third Pole: Journal of Geography, Volume 17, 2017

- To have good faith and respect on practices, costumes, different castes, languages, genders, occupations, religions and fairs and festivals

- To show love, reverence and devotion to the nation and to behave according to the norms and values of democracy (Loktantra).

- To get inspiration from the deeds of local community and famous people of national level and to show respect on them.

- To identify various social problems and be helpful to solve them.

- To be aware of human right, child right and one's duties and show it in practical life.

- To obey social codes and rules.

- To be able to explain the formation and functions of different local bodies (ward/ village development committee/municipality and district development committee

- To be able to observe and explain the immediate geographical features and practice on drawing map.

- To give a short introduction of the earth and to explain the geographical feature of Nepal.

- To be able to give a short introduction of neighboring countries.

- To say the historical background of one's community and the country

- To respect work and to form a habit of labor and economy, and

- To observe and explain about the local economic activities and to contribute in them as far as possible.

Whilereviewing the class-wise objectives of the social studies curriculum it has difficulties to link student's age level and the learning objectifies. The grade 1-3 encompasses the 6 -8 years group of children. However, giving the objectives and terminologies like social evils, untouchably, conservatism, different castes, languages, reverence and devotion to the nation and to behave according to the norms and values of democracy (Loktantra) are some examples of very high level of content. Similarly, many abstract points of understanding like to get inspiration from the deeds of local community and famous people of national level and to show respect to them, to be aware of human right, child right and one's duties and show it in practical life, to obey social codes and rules, to give a short introduction of the earth and to explain the geographical feature of Nepal and to 
Krishna Prasad Poudel / Space of Geography Content in Social Studies of School Education ...

be able to give a short introduction of neighboring countries are some of such examples which seems to not only difficult on linking the children of up to 8 years of age but also very hard to gain the learning practices and knowledge of such deeper facts.

The geography is placed within the unit of our earth. As per the grade-wise learning objectives, the main objectives of the geographical portion are to be enable students to observe and explain the immediate geographical features and practice on drawing map; to give a short introduction of the earth and to explain the geographical feature of $\mathrm{Nepal}$; and to enable then to give a short introduction of neighboring countries. It would be interesting to note it here that the unit is named our earth which seems very abstract and hard to relate the age level of the child to understand the terminology. Similarly, the textbook of class one has given the concept of drawing map through sketching the house, school and class-room. In the geographical knowledge the drawing of map is not like to sketch a house. The units of neighboring countries India and China have been given in the grade 4. It does not seem practicable to give the geographical knowledge of neighboring countries without having the knowledge of geography of Nepal.

The social studies curriculum for grade 6 to 8 has upgraded the units from the lower grades and further added emphasis on population's studies. Geography is placed within the unit of our earth. However, geographical studies are not in its synchronized way according to its domain. Physical geography, regional geography, and mathematical geography are mixed without the specific learning objectives. Regional study of geography of Nepal is given in grade 7, however, some concept of district and aerial differences are talked in grade 6 . The contents are not properly arranged and grade-wise objectives are not clearly specified according to the branches of geography, their learning objectives and importance of the topics through local to global contexts. Similarly, population of Nepal belongs to the part of geographical lesson, but the separate units are given in the curriculum.

The CDC has published the secondary level (Grade 9 and 10) curriculum 2014 along with the revised specific objectives and curriculum details of all compulsory subjects (CDC, 2016), in which Social studies is one of the compulsory subjects having weekly weightage 5 hours and 100 full markswith $75 \%$ theoretical examination and $25 \%$ for 
the practical mode of evaluation. The subject has incorporated 9 specific units with fixed weightage (Table 1).

Table 1: Social studies curriculum for grade 9 and 10

\begin{tabular}{lllr}
\hline \multirow{2}{*}{ SN } & \multicolumn{1}{c}{ Unit details } & $\begin{array}{c}\text { Annual time } \\
\text { allocation }\end{array}$ & $\%$ \\
\hline 1 & We and our society & 15 & 8.8 \\
2 & Development and development infrastructure & 16 & 9.4 \\
3 & Our tradition, social values and norms & 16 & 9.4 \\
4 & Social problems and solutions & 19 & 11.2 \\
5 & Civic sense & 22 & 12.9 \\
6 & Our earth & 27 & 15.9 \\
7 & Our past & 22 & 12.9 \\
8 & Economic activities & 18 & 10.6 \\
9 & Our international relationship and co-operations & 15 & 8.8 \\
\hline Total & & 170 hours & 100 \\
\hline
\end{tabular}

Source: $C D C, 2016$

These units are almost the same in curriculum structure from the grade 1 to 5 , however, from grade 6-8 there are some addition of population and demographic units which are omitted here. The document has specified certain achievements of students after the implementation of the curriculum (CDC, 2016, p. 135 and 136, the translated version is given here).

- Concept of human development indices and human development situation in Nepal

- Understand the basis of development of Nepal and concept of regional and sustainable development and introduction of development programme in Nepal

- Concept of social development, understand the types of society and elements of better society, and contribution to the socialization

- understand our tradition, social values and norms, the importance of culture, arts and literature and support for their conservation activities

- Achieve the knowledge on peace and conflict resolution, development of coherence and co-existence, work for the honor of senior citizens 
Krishna Prasad Poudel / Space of Geography Content in Social Studies of School Education ...

- Understand the contribution of national and international heroes and adaptation of their good deeds

- Identification of social problems, search of best alternatives to solve the problems and understand the role of civil society and individuals

- Introduction to constitution and constitutional development in Nepal, and presentation of constitutional organization of Nepal

- Introduction of human rights, good governance, democracy, civil society and rule of law

- Perceive the importance of physical features, climate, and their influence in human activities in Nepal

- Study and use of map and globe

- Understand the climate of world and its influencing factors and impact of climate on human activities

- A brief introduction of the physical, human and economic activities of the different continents of the world.

- Disaster risk reduction and management in water-induced disaster, earthquake and tsunami and its mitigation

- Search on historical and archeological resources of Nepal, participation on their conservation and protection, respect the great contributors of the country

- A brief understanding and description of political and economic events of the world

- Understand the contribution of agriculture, industries, trade and transport, foreign labor and co-operatives in the economic development of the country

- Introduction to economic structural plans, importance and current economic development plan of Nepal

- Understand the banking and finance institutions and government revenue systems and contribution on economic activities of the country

- Achieve the knowledge on contribution of international donor agencies, United Nation's Organizations, and other international organization and co-operation and the international relationship of Nepal 
- Understand the conceptual basis of international relationships, localization and globalization in their impacts on contemporary events

The curriculum has envisaged 21 different achievements after the implementation of social studies curriculum in grade 9 and 10. Different contents are also prescribed accordingly. Among the prescribed contents the share of geography is around $16 \%$. However, the share of geography (our earth) unit is the longest among the prescribed units, but the weightage of geography is somehow more widely structured covering from Nepal to global context. The structure of the geography contents are not in sequential orders according to the widely accepted branching system of the subject. The interesting point to note here is the tsunami disaster which is not relevant in the context of Nepal. It would be better to include the disasters like snow avalanches, flash floods or GLOF, landslide, floods, lightening, cold wave and hailstone in the Nepalese context. In the context of contemporary development the geography contents would be more appropriate to include the federal, provincial or regional study and curriculum development towards that direction which is not covered by the CDC. Similarly, the regional development concept has to be revisited along with the development modalities of the nation. Therefore, it is required to restructure the geography contents along with the widely accepted sequential order and philosophical basis and branching systems.

\section{The Findings}

The addition and deletion of subjects in the school curriculum are very sensitive issues; however, the National Curriculum Framework for School Education in Nepal, an official document of Curriculum Development Center (CDC, 2007) clearly mentioned that the decisions regarding the management of subjects to be offered were taken without comprehensive studies and recommendations (CDC, 2007, p. 24). Large coverage of the government documents including National Education Plan (NEC, 1992), National Curriculum Framework for School Education in Nepal (CDC, 2007), SSRP 20092013 (MoE, 2009) and SSDP 2016/17-2022/23 (MoE, 2016) have strongly pleaded the quality education, effective governance, improvement on educational infrastructure, development of public accountability for the education system but hardly given emphasis on basic educational pillars for better learning the reality of the country through its geographical diversities, cultural values, historical processes of existence, civics rights and duties for the nation and its economic potentialities. Most of the teaching contents are compiled from the social sciences and contemporary slogan-based agendas and social issues. Without having better understanding of deeper philosophical roots of 
Krishna Prasad Poudel / Space of Geography Content in Social Studies of School Education ...

disciplinary subjects, it is hard to attain the vision and goals of moral education, skillbased education and value system from the young generation as envisaged by the SSDP (MoE, 2016).

There are redundancies appeared in the social studies education in Nepal. the Health, Population and Environment is a separate compulsory subject in the school education, but two units of population, demographic characteristics, population distribution are included in grade 6 - 8 curriculum, which seems to be irrelevant. Besides that Population Education is a separate optional I subject in the school education. It shows that due to these duplications the weightage of social studies is reduced.

According to the international practice, geography is placed in the people, place and environment thematic content within the integrated form. But in Nepal the practice of designing social studies course is more inclined towards the pillar system, however, in several places of official documents it is claimed an integrated subject but in reality that is not appeared. Therefore, the social studies course is required to develop following the international practice as recommended by the NCSS (2010) and geography is one of the major thematic areas among them. The importance of geography of the country is neglected from the vision of education experts as it is evident from the NCF (2007). Similarly, the contents are not well structured. Thematic areas are not properly organized. Maps and sketches are placed together without any separation. In several practical exercise part geographical questions are designed to memories the name of country, capital, place, river and so on. Age limit of students and their psychological learning levels are not considered on prescribing the geography content. The content of geography of India and China are placed before the geography of Nepal in the name of our neighboring countries. Contents of geography within the social studies curriculum are prescribed without considering the horizontal and vertical linkages of the courses. Contents of geography are the only thematic areas covered the whole world within the social studies curriculum. It shows the imbalance within the thematic contents of present social studies course, despite not including the learning achievements as prescribed by the NCF (2007).

Therefore, social studies curriculum from basic/primary to the higher secondary education should include the cultural values, social diversities, historical process of nation building, geographical diversities of the country, civics right and duties, economic potentialities, along with the contribution of scientific development within 
the country, humanities, and mathematical innovations as envisaged by Barr, Barth and Shermis, (1977), NCSS (1993, 2001, 2010 ), Manitoba Educators (2005), Misco and Hamot (2012), and Adediran and Adenike (2013). The curriculum of the social studies at school needs to be developed along with the country's realities with reference to the international general knowledge. First priority should be confined to the national territory. After the social studies education citizens should know the nation's diverse realities and its potentialities for the future development. The education would achieve the vision of nation building though knowledge, skill and value-based citizens through the inspiration from the past events, understanding the present situation and potentialities for the implementation in the future actions.

\section{Conclusion}

From these discussions and findings the following points have been concluded:

- Geography of the country is a major thematic area within the SEE and it should be addressed properly in every curriculum related policy and plan document of the government sector.

- Curriculum of SSE has to be developed according to the global practice and tradition by identifying major thematic areas.

- Following the international practice of social studies curriculum the geography content should be limited within the country specific (i.e. geography of Nepal) up to grade 8 , geography of neighboring countries for grade 9 and 10 , and other continents at higher secondary levels (11 and 12).

- Map and map reading skills of local areas need to be focused at the basic education level (grade 1-8).

- The contents like Disaster Risk Reduction and Management (DRRM), mitigation, climate change adaption, workplace safety, population and environment are the contents of the geography which can be incorporated within the place, people and environment thematic areas.

- The curriculum needs to be developed according to the contemporary changes of the nation. Therefore, the study of local level, province and federal geographical units 
Krishna Prasad Poudel / Space of Geography Content in Social Studies of School Education ...

should be included with proper areal study. Similarly, the lessons of development regions and structural plan and periodic plan of the nation should be revised accordingly.

\section{References}

Adediran, A. A. and Adenike, O. C. (2013). Social Studies Education: An Imperative for the Promotion of Cultural Values for National Integration in Nigeria. Research on Humanities and Social Sciences, Vol.3, No.9, www.iiste.org.

Barr, R. D., Barth, J. L., and Shermis, S. S. (1977). Defining the social studies. Washington: National Council for the Social Studies.

CDC(2007).NationalCurriculum Frameworkfor SchoolEducation in Nepal.Curriculum

Development Center, Ministry of Education and Sports Government of Nepal,

CDC, (2008).Primary Education Curriculum 2063 Grade 1-3.Sanothimi, Bhaktapur:

Curriculum Development Center, Ministry of Education and Sports, Government of Nepal,

CDC, (2016).Secondary School Curriculum Class 9-10, 2014 (Madhyamic sikshya pathyakram katshya 9-10, 2071 B.S.), Sanothimi, Bhaktapur: Curriculum development Center, Ministry of Education, Government of Nepal,

HMG.(1971).The National Education System Plan for 1971-76.Ministry of Education His Majesty's Government of Nepal.

Manitoba Education, Citizenship and Youth, (2005).Connecting and belonging : a foundation for implementation, the Crown in Right of Manitoba as represented by the Minister of Education, Citizenship and Youth. Winnipeg, Manitoba: Manitoba Education, Citizenship and Youth, School Programs Division,

Misco, T and Hamot, G. E. (2012). "He was the opposite of what we learned a teacher should be": A Study of Preservice Social Studies Students' Cooperating Teachers 1 The Journal of Social Studies Research, Volume 36, Issue 4

MOE.(2009), School Sector Reform Plan 2009-2015.Kesharmahal, Kathmandu: Ministry of Education, Government of Nepal

MoE, (2016).School Sector Development Plan 2016/17-2022/23. Kathmandu: Ministry of Education, Government of Nepal, 
The Third Pole: Journal of Geography, Volume 17, 2017

National Council for the Social Studies, (1994).Expectations for Excellence: Curriculum Standards for the Social Studies. Washington, D.C: NCSS.

NCSS (2010).National Curriculum Standards for Social Studies: A Framework for Teaching, Learning, and Assessment Developed by National Council for the Social Studies. Maryland, Silver Spring,

NEC (1992).Report of The National Education Commission, 1992. National Education Commission KesharMahal, Kathmandu, Nepal

Parker, Walter C. (2010).A "Sampler" of the (revised) National Curriculum Standards for Social Studies.NCSS,

The Bureau of Publications College of Education, 1956.Education in Nepal report of the Nepal National Education Planning Commission, Report of the educational advisor to the commission, The Bureau of Publications College of Education, Kathmandu, Nepal

Zarrillo, J. J. (2012). Teaching Elementary Social Studies: Principles and Applications (4th Edition. Boston: Pearson, https://www.amazon.com/Teaching-ElementarySocial-Studies-Applications/dp/013256551X

https://www.education.com/reference/article/definitions-social-studies/

https://scholar.google.com/scholar?q=NCSS+Task+Force+on+Revitalizing + Citizenshi p+Education, $+2001,+$ p. +319

http://www.merriam-webster.com/dictionary/social\%20studies)

https://www.education.com/reference/article/ten-themes-social-studies-standards/

https://www.socialstudies.org/standards/teacherstandards

www.iiste.org 